\title{
Slide Mode Control for Integrated Electric Parking Brake System
}

\author{
Bin Wang, ${ }^{1}$ Xuexun Guo, ${ }^{1}$ Chengcai Zhang, ${ }^{1}$ Zhe Xiong, ${ }^{1}$ Huan Xia, ${ }^{1}$ and Jie Zhang ${ }^{2}$ \\ ${ }^{1}$ Hubei Key Laboratory of Advanced Technology of Automotive Parts, Wuhan University of Technology, Wuhan 430070, China \\ ${ }^{2}$ Wanxiang Group Technology Center, Hangzhou 310000, China
}

Correspondence should be addressed to Xuexun Guo; guoxx@whut.edu.cn

Received 25 October 2013; Accepted 27 October 2013

Academic Editor: Hui Zhang

Copyright (C) 2013 Bin Wang et al. This is an open access article distributed under the Creative Commons Attribution License, which permits unrestricted use, distribution, and reproduction in any medium, provided the original work is properly cited.

\begin{abstract}
The emerging integrated electric parking brake (IEPB) system is introduced and studied. Through analyzing the various working stages, the stages switched IEPB system models are given with the consideration of the friction and system idle inertia. The sliding mode control (SMC) method is adopted to control the clamping force by the widely used motor angle and clamping force relationship method. Based on the characteristics of the state equations, two sliding surfaces are built to control the motor angle and current, respectively. And in every working stage, the control stability is guaranteed by choosing the control parameters based on Lyapunov theory and SMC reachability. The effectiveness of the proposed control system has been validated in Matlab/Simulink.
\end{abstract}

\section{Introduction}

Lots of strong points exist in X-by-wire systems, such as component number reduction, weight reduction, and performance improvement $[1,2]$. Electronic parking brake (EPB) system is one kind of brake-by-wire systems, which generates the parking force by motor torque instead of the manual force. Hence, the EPB system can increase the vehicle cabin space, facilitate the parking process, and have potential function [3]. There are mainly two kinds of EPB: the first one generates the force by pulling down traditional parking cable, as seen in [3-9]. The second one is called integrated EPB (IEPB), which has the similar structure with the electromechanical brake [10-12] and hence it can offer numerous possibilities [13]. IEPB actuator is mounted on the traditional caliper. Through screw-nut structure, the rotating movement from the DC motor can be transformed to the rectilinear motion of the nut [14]. By the moving forward or backward of the nut, the braking force can be generated or released. Once the desired braking force is reached, the motor power can be cut off and the clamping force can be steady due to the screw-nut self-locking.

While IEPB system has been used in some advanced sedans $[15,16]$, there is very little published research. For EPB with traditional cables, Lee et al. studied the bang-bang $[4]$, nonlinear P controllers $[3,6,7]$ to control the clamping force and the controller stability is also analyzed in $[3,7]$. The traditional EPB system models were built in [3-7]; however, motor friction and screw-nut system inertia were neglected. Actually, during the motor idle stage, the motor friction and the nut inertia have direct effects on the modeling precision. For IEPB system, due to the limited installation space and the high cost of force sensor, clamping force estimation methods based on the motor position have been proposed in $[1,10-$ 12]. From the researches [10-12, 17], we know based on the angular displacement of the motor that the clamping force can be estimated precisely. However, few control methods that can track the desired motor angle precisely for electric parking brake system are shown in published researches. Especially, robust control, hardly guaranteed by the published control methods, is very important for vehicle safety system $[18,19]$. Hence, the authors proposed the sliding mode control method based on the system characteristics to optimize the control precision and robustness [20-22].

The present authors have made much effort over a long time to research and develop EPB system [14, 23, 24]. And to the authors' best knowledge, little published research is about the IEPB system. The main contributions of this paper lie in three aspects. First, this is among the first attempts to develop a detailed system model for IEPB system. In particular, the state-switched system stages and also the motor and screwnut friction model are considered seriously. Second, this is 


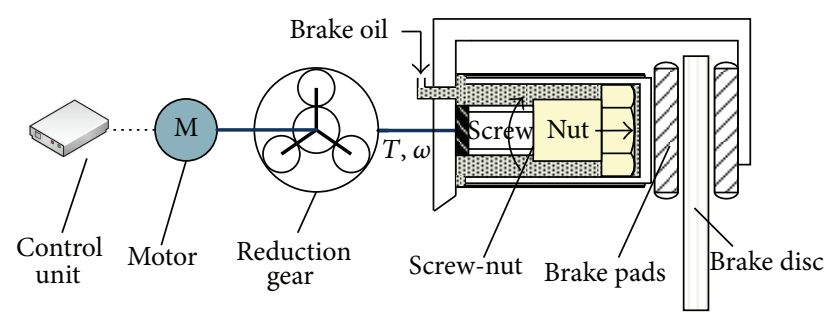

FIGURE 1: Structure of the IEPB system.

the first attempt to integrate a sliding mode control (SMC) method with EPB system. Through the SMC method, both the precision and robustness of IEPB system are improved apparently. Third, two sliding surfaces are designed to improve the control performance and the control system stability is studied based on Lyapunov theory and system reachability.

The rest of this paper is organized as follows. In the second section, principle and model of the state-dependent IEPB system, including the DC motor and screw-nut system as well as the clamping force, are given. The third section proposed the SMC control law with the proof of the control stability. The simulations and analyses of the proposed control system are shown in the fourth section, followed by the concluding remarks in the final section.

\section{System Modeling}

In this section, the system structure and system modeling will be presented. The IEPB is a system that locks the vehicle wheels steadily by controlling the motor when receiving the parking brake command. The structure of IEPB system is shown in Figure 1, including DC motor, reduction gears, screw-nut module, traditional brake pads, and disc.

2.1. DC Motor. In IEPB system, the final parking braking force is provided by the motor torque. As shown in Figure 1, motor torque is first transferred to the reduction gears for increasing the driven torque. The model of DC motor can be built as

$$
\begin{gathered}
U=L_{a} \dot{i}_{a}+R_{a} i_{a}+K_{\mathrm{emf}} \omega, \\
K_{\text {motor }} i_{a}=J_{m} \dot{\omega}_{m}+T_{F}+T_{G}, \\
T_{m}=K_{\text {motor }} i_{a},
\end{gathered}
$$

where $U$ is the motor voltage; $L_{a}$ is the inductance; $i_{a}$ is the motor current; $R_{a}$ is the resistance; $K_{\text {emf }}$ is the EMF constant; $\omega$ is the angular rate; $T_{m}$ is motor torque; $K_{\text {motor }}$ is motor constant; $T_{F}$ is the friction torque, including the viscous friction, dynamical friction $T_{F C}$, and the maximum static friction $T_{F \max } ; T_{G}$ is the load torque; $J_{m}$ is the moment of inertia of this system. Based on the Armstrong friction model [25], the friction torque of DC motor can be described as

$$
T_{F}=T_{F C}+\left(T_{F \max }-T_{F C}\right) e^{-\mid \omega / \omega_{s} \delta_{s}^{\delta_{s}}}+b_{v} \omega, \quad(\omega \neq 0),
$$

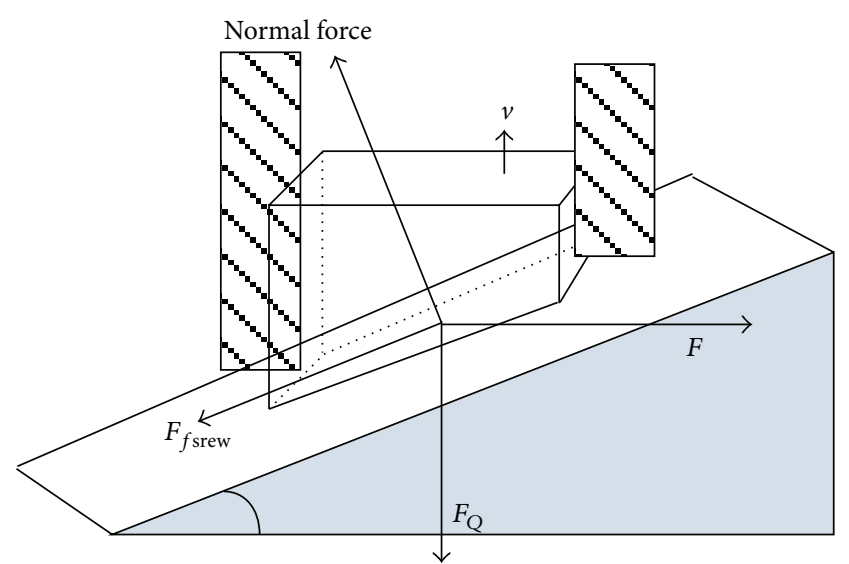

FIgURE 2: The equivalent structure of screw-nut.

where $\omega_{s}$ is the Stribeck velocity that describes the continuous decrease instead of the break point; $\delta_{s}$ is a coefficient for Stribeck friction.

For simplicity of the analysis, the friction torque can be written as

$$
T_{F}=b_{v} \omega_{m}
$$

2.2. Screw-Nut System. In IEPBs, the nut can just move in the axial direction, secured against twisting; on the contrary, the screw can just rotate without moving forward or backward. When the screw rotates in counter-clockwise direction, the head will move forward to the left side in the axial direction. Figure 2 shows the equivalent structure of the screw-nut. The lower wedge denotes the screw while the upper one denotes the nut. Therefore, the relative motion for nut and screw can be seen as the nut is sliding along the slope with an angle inclination $\alpha$ [26-28].

According to the equivalent schematic diagram of screwnut, the relationship between the screw torque $T_{L}$ and $F$ can be described as

$$
\begin{gathered}
N \cdot T_{G}=T_{L}, \\
T_{L}=F \cdot r,
\end{gathered}
$$

where $N$ is the gear ratio between the motor and the IEPB actuator; $r$ is the screw pitch radius; $F$ is the equivalent force on the nut cross section shown in Figure 2. When the nut is moving on the screw, the friction force $F_{f \text { srew }}$ in the screw-nut system can be written as

$$
F_{f \text { srew }}=F_{\text {coulomb }_{-} f}+\left(F_{\text {max }_{-} f}-F_{\text {coulomb }_{-} f}\right) e^{-\left|v / v_{s}\right|^{2}}+c_{v} v,
$$

where $F_{f \text { srew }}$ is the friction force of the screw-nut system; $v_{s}$ is the Stribeck velocity; $c_{v}$ is the viscous friction coefficient; $F_{\max _{-} f}$ is the maximum static friction; $F_{\text {coulomb }_{-} f}$ is the coulomb friction proportional to the normal force.

Due to the clearance existing between the nut and the brake disc, the nut needs to move forward first to clear this 


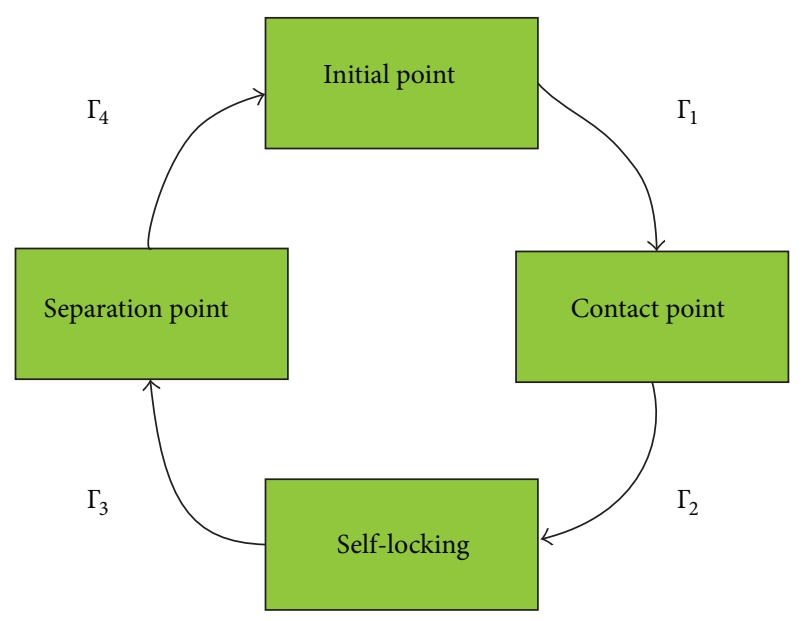

FIGURE 3: State switched screw-nut system.

gap. This status is named $\Gamma_{1}$ as shown in Figure 3 and it is obvious that there is no clamping force due to no contacting during $\Gamma_{1}$. However, in order to estimate the contact point precisely, the friction torque analysis in screw-nut system is still needed. Stages $\Gamma_{1}$ and $\Gamma_{4}$ have the similar dynamics equations though the speed direction is contrary. While Stages $\Gamma_{2}$ and $\Gamma_{3}$ have the similar dynamics equations, they have a contrary speed direction. Hence, for simplicity of the modeling process, only $\Gamma_{1}$ and $\Gamma_{2}$ are analyzed in this paper.

For Stages $\Gamma_{1}$. Due to no clamping force in $\Gamma_{1}$, the friction force can be written as

$$
F \cdot \cos \alpha=F_{f \text { srew }}
$$

where $\alpha$ is the lead angle. When there is no contact, the $F_{\text {coulomb } f}$ can be ignored and the viscous friction is playing a leading role in (5). Substituting (3) and (4) into (6), it yields

$$
\begin{aligned}
& \frac{c_{v} \dot{x}_{\text {nut }}}{\sin \alpha}+\frac{m \ddot{x}_{\text {nut }}}{\sin \alpha}=T_{L} \cdot \cos \alpha, \\
& T_{L}=2 r \cdot \frac{c_{v} \dot{x}_{\text {nut }}+m_{\text {nut }} \ddot{x}_{\text {nut }}}{\sin 2 \alpha},
\end{aligned}
$$

where $m$ is the mass of the nut. The state equations for the IEPBs in $\Gamma_{1}$ can be presented as

$$
\frac{d}{d t}\left[\begin{array}{c}
i \\
\omega \\
\theta
\end{array}\right]=\left[\begin{array}{c}
-\frac{R_{a}}{L_{a}} i-\frac{K_{\mathrm{emf}}}{L_{a}} \omega+\frac{1}{L_{a}} U \\
\frac{K_{\mathrm{motor}} i}{J_{m}}-\frac{b_{v} \omega}{J_{m}}-\frac{2 r\left(c_{v} \dot{x}_{\mathrm{nut}}+m_{\mathrm{nut}} \ddot{x}_{\mathrm{nut}}\right)}{J_{m} N \sin 2 \alpha} \\
\omega
\end{array}\right]
$$

For Stages $\Gamma_{2}$. During the clamping stage $\Gamma_{2}$, based on the horizontal and perpendicular forces on the contact surface in Figure 2 and due to the much higher magnitude coulomb friction force, the friction force can be written as

$$
F_{f_{\text {srew }}}= \begin{cases}\frac{1}{r} T_{L} \cos \alpha-F_{Q} \sin \alpha & v=0, \Delta F<F_{\max _{-} f} \\ F_{\max _{-} f} \operatorname{sgn}(\Delta F) & v=0, \Delta F \geq F_{\max _{-} f} \\ \mu_{s} \cdot \frac{T_{L} \sin \alpha+F_{Q} \cos \alpha r}{r} & v \neq 0,\end{cases}
$$

where $\mu_{s}$ is the coulomb friction coefficient; $F_{\mathrm{Q}}$ is the axial load on the nut; $\Delta F$ is the external force, deciding the friction direction. Ignoring the little inertia effect of the nut mass during $\Gamma_{2}$ for simplifying modeling, according to Figure 2 , the relationship between the screw torque $T_{L}$ and the head load $F_{\mathrm{Q}}$ can be written as

$$
T_{L} \cdot \frac{1}{r \cdot \tan \left(\alpha+\arctan \mu_{s}\right)}=F_{\mathrm{Q}}+m_{\text {nut }} \ddot{x}_{\text {nut }},
$$

where $m_{\text {nut }}$ is the mass of head and $x_{\text {nut }}$ is the linear displacement of head.

According to (8)-(11), the $T_{L}$ can be written as

$$
T_{L}= \begin{cases}2 r \cdot \frac{c_{v} \dot{x}_{\text {nut }}+m_{\text {nut }} \ddot{x}_{\text {nut }}}{\sin 2 \alpha} & \text { during } \Gamma_{1} \\ \frac{F_{Q}+m_{\text {nut }} \ddot{x}_{\text {nut }}}{\sigma_{1}} & \text { during } \Gamma_{2},\end{cases}
$$

where

$$
\sigma_{n}=\frac{1}{r \cdot \tan (\arctan \mu+\alpha)} .
$$

2.3. Clamping Force Model. As shown in Figure 4, $A_{0}, A_{c}$, and $A_{1}$ are three points, namely, the nut initial point, nut contact point, and the system contact point, respectively. In clamping maneuver, the nut moves from point $A_{0}$ to point $A_{c}$ and then pushes the pads to clamp the disc and then moves back to initial point $A_{0}$ during $\Gamma_{3,4}$. Line $d_{1}$ is the gap between the nut initial position $A_{0}$ and the piston position. Line $d_{2}$ is the total thickness of pad and piston and is a constant value under no pressure. To simplify analyses, the piston and pad are considered as an assembly and we assume no gap exists between the pad and piston. Line $d_{3}$ represents the gap between the friction pads to braking disc, which can be guaranteed by the seal groove mechanism. Line $d_{4}$ is not shown in Figure 4, since it is the deformation value. With the gap cleared, clamping force will be generated by the nut translational motion.

Nut rectilinear movement $x_{\text {nut }}$ can be written as

$$
x_{\text {nut }}=d_{1}+d_{3}+d_{4} \text {. }
$$

Based on Newton's laws of motion, the clamping force can be written as

$$
F_{\mathrm{Q}}(t)=2 \cdot\left(k_{\text {brake }} \cdot d_{4}(t)+b_{\text {brake }} \cdot \dot{d}_{4}(t)\right),
$$




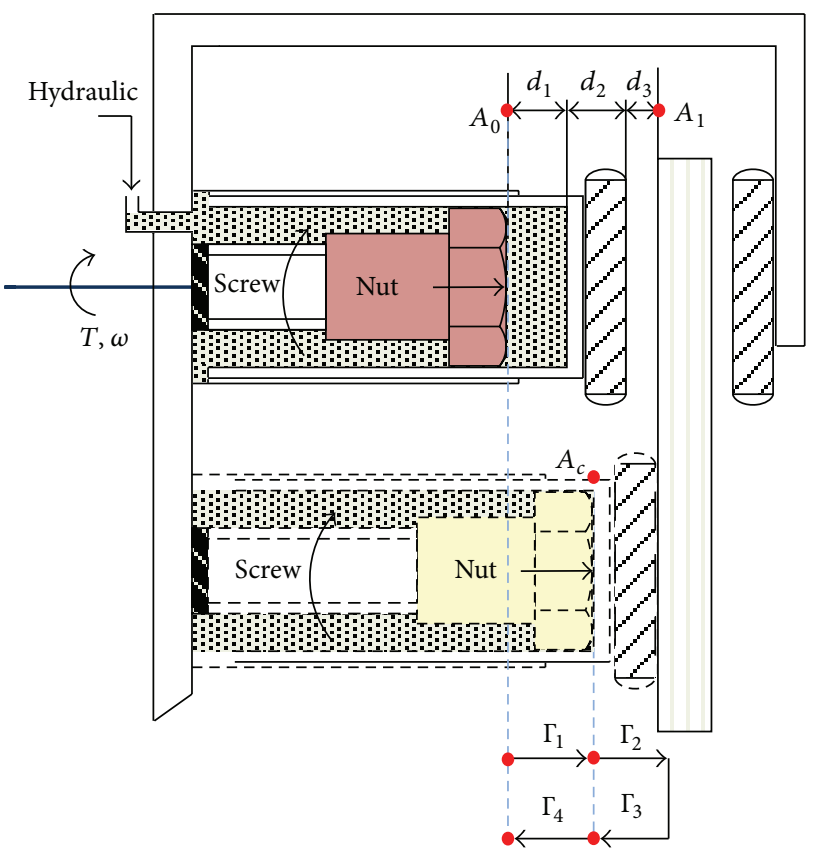

FIGURE 4: Schematic diagram of the IEPBs.

where $b_{\text {brake }}$ is the damping coefficient and the overall stiffness of actuator $k_{\text {brake }}$ can be calculated from each individual part [1]:

$$
k_{\text {brake }}=\frac{1}{1 / k_{\text {disk }}+1 / k_{\text {head }}+2 / k_{\text {pad }}+1 / k_{\text {caliper }}},
$$

where $k_{\text {brake }}$ is stiffness coefficient of the brake system; $k_{\text {disk }}$, $k_{\text {head }}, k_{\text {pad }}$, and $k_{\text {caliper }}$ are the stiffness coefficient of brake disc, nut, pad, and the caliper, respectively; $\theta_{L}$ is the angular displacement corresponding to the normal gap distance and is a constant value; $\theta$ is the total angular displacement, which can be described as

$$
\begin{gathered}
\frac{d_{1}+d_{3}}{\theta_{L}}=\frac{p}{2 \pi N}, \quad \frac{x_{\mathrm{nut}}}{\theta}=\frac{p}{2 \pi N}, \\
d_{4}=\frac{P}{2 \pi N} \tilde{\theta},
\end{gathered}
$$

where $\widetilde{\theta}=\left\{\begin{array}{c}\theta-\theta_{L}, \quad \theta>\theta_{L} \\ 0, \quad \theta \leq \theta_{L}\end{array}\right.$ is the active angular displacement corresponding to the compression movement $d_{4}$ and $p$ is the pitch of screw:

$$
F_{\mathrm{Q}}(t)=2 \cdot\left(k_{\text {brake }} \cdot \frac{P}{2 \pi N} \widetilde{\theta}+b_{\text {brake }} \cdot \frac{P}{2 \pi N} \dot{\tilde{\theta}}\right) .
$$

Based on (1) and (12)-(19), the state equations for the IEPBs in $\Gamma_{2}$ can be presented as

$$
\begin{aligned}
& \frac{d}{d t}\left[\begin{array}{c}
i \\
\omega \\
\theta
\end{array}\right] \\
& =\left[\begin{array}{c}
-\frac{R_{a}}{L_{a}} i-\frac{K_{\mathrm{emf}}}{L_{a}} \omega+\frac{1}{L_{a}} U \\
\frac{K_{\text {motor }} i}{J_{m}}-\frac{b_{v} \omega}{J_{m}}-\frac{p k_{\text {brake }} \tilde{\theta}+p b_{\text {brake }} \omega+m_{\text {head }} p \ddot{\theta}}{2 J_{m} \pi \sigma_{1} N^{2}} \\
\omega
\end{array}\right] .
\end{aligned}
$$

\section{Control Design}

Based on (15) and researches in $[1,3-7,12]$, we know that the clamping force has a direct relationship with the motor angle. In this paper, a robust control system is designed to track the desired motor angle precisely and then to reach the desired force. Rearranging (9) into standard state space for stage $\Gamma_{1}$ yields

$$
\frac{d}{d t}\left[\begin{array}{c}
i \\
\omega \\
\theta
\end{array}\right]=A_{\Gamma_{1}}\left[\begin{array}{c}
i \\
\omega \\
\theta
\end{array}\right]+B_{\Gamma_{1}} U
$$

where

$$
\begin{gathered}
A_{\Gamma_{1}}=\left[\begin{array}{ccc}
-\frac{R_{a}}{L_{a}} & -\frac{K_{\mathrm{emf}}}{L_{a}} & 0 \\
K_{\text {motor }} \xi & -\left(b_{v}+\psi\right) \xi & 0 \\
0 & 1 & 0
\end{array}\right], \\
B_{\Gamma_{1}}=\left[\begin{array}{c}
\frac{1}{L_{a}} \\
0 \\
0
\end{array}\right] \\
\psi=\frac{\mathrm{rcp}}{\pi N^{2} \sin 2 \alpha}, \\
\xi=\frac{\pi N^{2} \sin 2 \alpha}{J_{m} \pi N^{2} \sin 2 \alpha+\mathrm{rpm}_{\mathrm{nut}}} .
\end{gathered}
$$

Rearranging (20) into standard state space for state $\Gamma_{2}$ yields

$$
\frac{d}{d t}\left[\begin{array}{c}
i \\
\omega \\
\theta
\end{array}\right]=A_{\Gamma_{2}}\left[\begin{array}{c}
i \\
\omega \\
\theta
\end{array}\right]+B_{\Gamma_{2}} U
$$




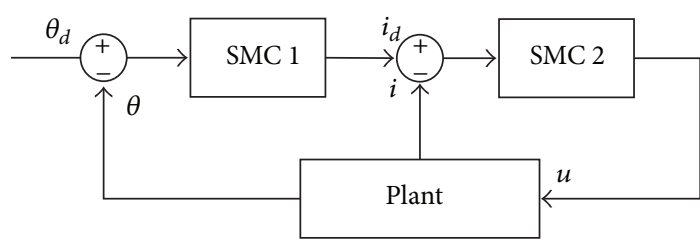

FIGURE 5: Schematic diagram of the SMC system.

where

$$
\begin{gathered}
A_{\Gamma_{2}}=\left[\begin{array}{ccc}
-\frac{R_{a}}{L_{a}} & -\frac{K_{\mathrm{emf}}}{L_{a}} & 0 \\
K_{\text {motor }} \varphi_{n} & -\left(b_{v}+\kappa_{n}\right) \varphi_{n} & -\delta_{n} \varphi_{n} \\
0 & 1 & 0
\end{array}\right], \\
B_{\Gamma_{2}}=\left[\begin{array}{c}
\frac{1}{L_{a}} \\
0 \\
0
\end{array}\right],
\end{gathered}
$$

where

$$
\begin{gathered}
\kappa_{n}=\frac{p \cdot b_{\text {brake }}}{2 \pi \sigma_{n} N^{2}}, \\
\delta_{n}=\frac{p \cdot k_{\text {brake }}}{2 \pi \sigma_{n} N^{2}}, \\
\varphi_{n}=\frac{2 \pi \sigma_{n} N^{2}}{2 \pi \sigma_{n} J_{m} N^{2}+m_{\text {head }} p} .
\end{gathered}
$$

For all the dynamic stages $\Gamma_{1-4}$, the feedback can be chosen as

$$
y=\left[\begin{array}{lll}
0 & 0 & 1
\end{array}\right]\left[\begin{array}{c}
i \\
\omega \\
\theta
\end{array}\right] .
$$

3.1. Control Law Design. The control robustness is very important [29], especially for braking system. In this part, a sliding mode control (SMC) design procedure for the stateswitched IEPB system is presented, which mainly includes 2 steps: firstly, the design of the sliding surface; secondly, the design of the controller, by which the trajectory will be guided to sliding on the surface designed in step one. Note that the clamping force has a direct relationship with the angular displacement $\widetilde{\theta}$ based on (18) and (19). From (21), (26), and (29), we know the control input $u$ can just directly control the current; however, current $i$ has a relationship with the angular displacement. Hence, we define two sliding surfaces as shown in Figure 5 for angular displacement control and current control, respectively.

These two sliding surfaces are defined as

$$
\begin{gathered}
s_{1}=\dot{e}_{1}+g e_{1}, \quad(g>0) \\
s_{2}=i_{d}-i,
\end{gathered}
$$

where $s_{1}$ and $s_{2}$ are two sliding surfaces for angular displacement and motor current and $e_{1}=\theta_{d}^{*}-\theta, g$ is a positive gain.
The corresponding control inputs can be written as

$$
\begin{gathered}
i_{d}= \begin{cases}H_{1, \Gamma_{1}} \operatorname{sgn}\left(s_{1}\right)+\frac{s_{1}}{H_{1, \Gamma_{1}}}, & \text { during } \Gamma_{1} \\
H_{1, \Gamma_{2}} \operatorname{sgn}\left(s_{1}\right)+\frac{s_{1}}{H_{1, \Gamma_{2}}}, & \text { during } \Gamma_{2},\end{cases} \\
u= \begin{cases}H_{2, \Gamma_{1}} \operatorname{sgn}\left(s_{2}\right)+\frac{s_{2}}{H_{2, \Gamma_{1}}}, & \text { during } \Gamma_{1} \\
H_{2, \Gamma_{2}} \operatorname{sgn}\left(s_{2}\right)+\frac{s_{1}}{H_{2, \Gamma_{2}}}, & \text { during } \Gamma_{2},\end{cases}
\end{gathered}
$$

where $H_{i, \Gamma_{j}(i, j=1,2)}$ are the control parameters which need to be determined.

Remark 1. The current $i_{d}$ is a virtual input to connect the desired angular displacement and the actual control input $u$.

Remark 2. If $H_{i, \Gamma_{j}(i, j=1,2)}$ is a very small value and $1 / H_{i, \Gamma_{j}(i, j=1,2)}$ will be a large value, which can help reduce the chattering when the state trajectories are closing to the sliding surfaces and can also apply a higher gain for larger error.

Remark 3. $H_{i, \Gamma_{j}(i, j=1,2)}$ should be chosen to make the sliding surface satisfy the reachability condition as follows [20]:

$$
\frac{1}{2} \frac{d}{d t}\left(s(t)^{2}\right) \leq-\eta|s(t)|, \quad \eta>0 .
$$

Theorem 4. The SMC controller given in (31) is asymptotically stable if the gains are chosen as

$$
\begin{gathered}
H_{1, \Gamma_{1}}>\frac{\eta_{1}+\left|\left(b_{v} \xi+\psi \xi-g\right) \omega\right|}{K_{\text {motor }} \xi}, \\
H_{1, \Gamma_{2}}>\frac{\eta+\left|\left(b_{v}+\kappa_{n}-g\right) \omega\right|+\delta_{n} \varphi_{n} \theta}{K_{\text {motor }} \varphi_{n}} .
\end{gathered}
$$

Proof. Select a Lyapunov function candidate for $s_{1}$ as

$$
V_{1}=\frac{1}{2} s_{1}^{2},
$$

for stage $\Gamma_{1}$.

Substituting (21) and (22) into the first order derivative of (35) yields

$$
\begin{aligned}
\dot{V}_{1} & =\ddot{e}_{1}+g \dot{e}_{1}=-\left(\frac{d \omega}{d t}+g \omega\right) \\
& =\left(b_{v} \xi+\psi \xi-g\right) \omega-K_{\text {motor }} i \xi .
\end{aligned}
$$

Based on Remark 3, we have

$$
\frac{1}{2} \frac{d}{d t}\left(s_{1}(t)^{2}\right) \leq-\eta_{1}\left|s_{1}(t)\right|, \quad \eta_{1}>0,
$$

when $s_{1}>0$; substituting (31) and (36) into (37), we have

$$
\begin{gathered}
s_{1}\left[\left(b_{v} \xi+\psi \xi-g\right) \omega-K_{\text {motor }} i \xi\right] \leq-\eta_{1} s_{1}, \\
H_{1, s_{1}>0, \Gamma_{1}}>\frac{\eta_{1}+\left(b_{v} \xi+\psi \xi-g\right) \omega}{K_{\text {motor }} \xi},
\end{gathered}
$$


when $s_{1}<0$; we have

$$
\begin{gathered}
s_{1}\left[\left(b_{v} \xi+\psi \xi-g\right) \omega-K_{\text {motor }} i \xi\right] \leq-\eta_{1} s_{1}, \\
H_{1, s_{1}<0, \Gamma_{1}}>\frac{\eta_{1}-\left(b_{v} \xi+\psi \xi-g\right) \omega}{K_{\text {motor }} \xi} .
\end{gathered}
$$

Hence, based on (39) and (41), the reachability can be satisfied if

$$
H_{1, \Gamma_{1}}>\frac{\eta_{1}+\left|\left(b_{v} \xi+\psi \xi-g\right) \omega\right|}{K_{\text {motor }} \xi},
$$

for stage $\Gamma_{2}$.

Substituting (27) into the first time derivative of (35), we have

$$
\begin{aligned}
\dot{V}_{1} & =\ddot{e}_{1}+g \dot{e}_{1}=-\left(\frac{d \omega}{d t}+g \omega\right) \\
& =\left(b_{v}+\kappa_{n}-g\right) \omega+\delta_{n} \varphi_{n} \theta-K_{\text {motor }} \varphi_{n} i .
\end{aligned}
$$

According to Remark 3, the reachability needs to be satisfied,

$$
\frac{1}{2} \frac{d}{d t}\left(s_{1}(t)^{2}\right) \leq-\eta_{1}\left|s_{1}(t)\right|, \quad \eta_{1}>0,
$$

when $s_{1}>0$; substituting (31) and (43) into (44), we have

$$
\begin{array}{r}
\left(b_{v}+\kappa_{n}-g\right) \omega+\delta_{n} \varphi_{n} \theta-K_{\text {motor }} \varphi_{n} H_{1, \Gamma_{2}}<-\eta_{1}, \\
H_{1, s_{1}>0, \Gamma_{2}}>\frac{\eta_{1}+\left(b_{v}+\kappa_{n}-g\right) \omega+\delta_{n} \varphi_{n} \theta}{K_{\text {motor }} \varphi_{n}},
\end{array}
$$

when $s_{1}<0$,

$$
\begin{array}{r}
\left(b_{v}+\kappa_{n}-g\right) \omega+\delta_{n} \varphi_{n} \theta+K_{\text {motor }} \varphi_{n} H_{1, \Gamma_{2}}>\eta_{1} \\
H_{1, s_{1}<0, \Gamma_{2}}>\frac{\eta_{1}-\left(b_{v}+\kappa_{n}-g\right) \omega-\delta_{n} \varphi_{n} \theta}{K_{\text {motor }} \varphi_{n}} .
\end{array}
$$

Hence, based on (46) and (48), the reachability can be satisfied if

$$
H_{1, \Gamma_{2}}>\frac{\eta_{1}+\left|\left(b_{v}+\kappa_{n}-g\right) \omega\right|+\delta_{n} \varphi_{n} \theta}{K_{\text {motor }} \varphi_{n}}
$$

Theorem 5. The SMC controller given in (32) is asymptotically stable if the gains are chosen as

$$
H_{2} \geq \eta L_{a}+R_{a} i_{a}+K_{\mathrm{emf}} \omega
$$

which is the reaching condition for the sliding mode.

Note that due to the fact that Theorem 5 shares the same Lyapunov function with Theorem 4 , the proof will not be presented here.
TABLE 1: IEPBs simulation parameters.

\begin{tabular}{lcc}
\hline & $R_{a}$ & $0.465 \Omega$ \\
Motor $\left(25-30^{\circ} \mathrm{C}\right)$ & $K_{\mathrm{emf}}$ & $9.947 \mathrm{mV} / \mathrm{rad} / \mathrm{sec}$ \\
& $K_{\text {motor }}$ & $9.947 \mathrm{~m}-\mathrm{Nm} / \mathrm{Amp}$ \\
\hline Reduction gear & Gear ratio & $150: 1$ \\
\hline \multirow{2}{*}{ Screw-nut } & Pitch & $2 \mathrm{~mm}$ \\
& radius & $5 \mathrm{~mm}$ \\
\hline
\end{tabular}

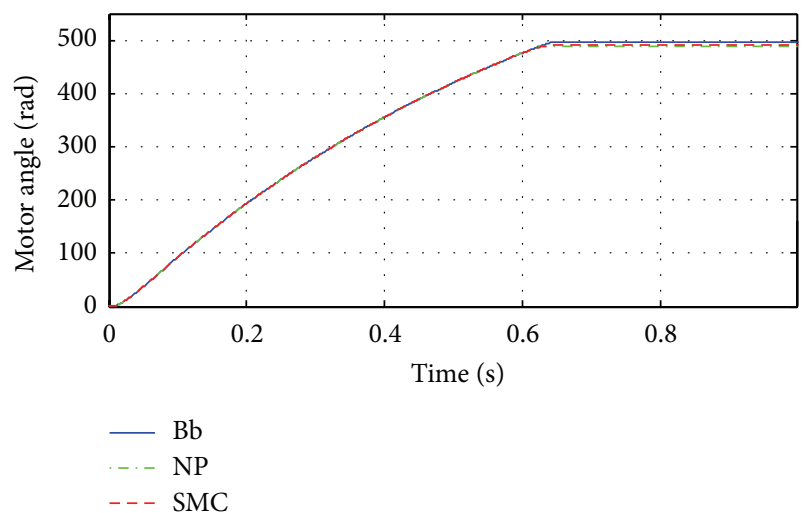

(a)

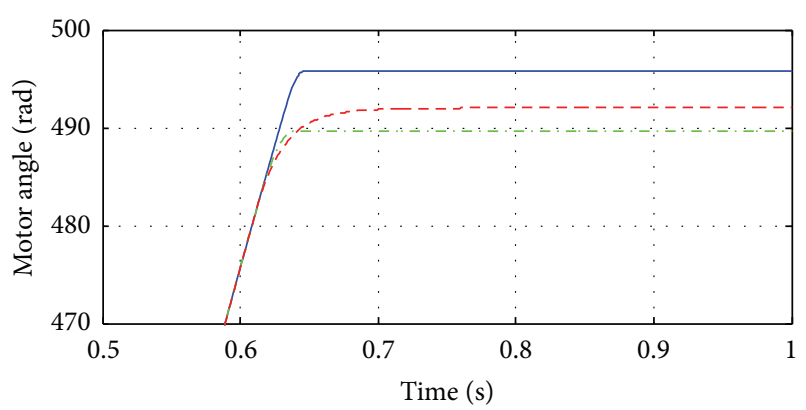

$-\mathrm{Bb}$
$-\cdots \mathrm{NP}$
$---\mathrm{SMC}$

(b)

FIGURE 6: Comparison among three control laws $\left(\theta_{d}=492 \mathrm{rad}\right)$. Bb: Bang-bang control. NP: nonlinear Proportion control. SMC: sliding mode control.

\section{Simulations and Discussions}

In this section, we will study the control performance of the proposed sliding mode control strategy by means of simulation examples. The system parameters and actuator parameters are given in Table 1. The proposed SMC control law is validated by simulation performed in Matlab/Simulink.

Figure 6 shows the target motor angle tracking performance between the Bang-bang control [4], nonlinear Proportion control $[3,7]$, and sliding mode control with the desired motor angle $492 \mathrm{rad}$. From Figure 6(a), it is obvious that before $0.6 \mathrm{sec}$, there is nearly no difference among these three controllers. From Figure 6(b), we can see that the Bangbang controller leads to a steady state error of 5 rad though it 


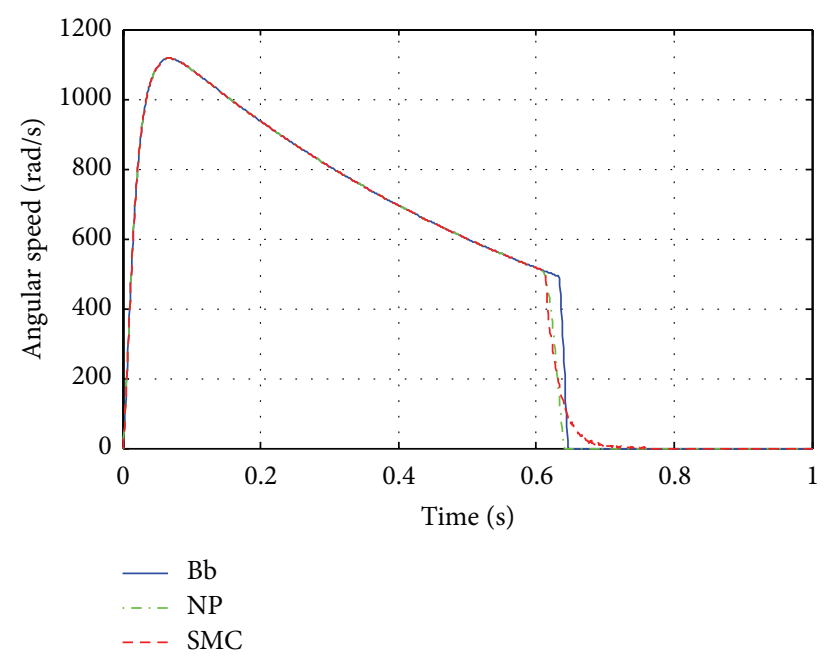

FIGURE 7: Motor speed comparisons among three control laws $\left(\theta_{d}=\right.$ $492 \mathrm{rad})$.

increases to the target first. The nonlinear $\mathrm{P}$ controller results in a negative error of $2 \mathrm{rad}$. In SMC, it is easy to notice that when the motor angle is closing to the target, the gradient is decreasing gradually due to the effects of sliding surfaces. And the SMC controller reaches the 492 rad precisely. Note that for common parking brake maybe the larger force may not lead to dangerous situations. However, IEPBs should have the ability to track the target precisely, because $1 \mathrm{rad}$ angle error can cause hundreds of Newton force error, which may lead to serious condition during the dynamic braking maneuver. On the other hand, compared with the desired clamping force, a larger one can also lead to a releasing problem, since during the releasing mode, the motor needs to rotate contrarily. With the larger clamping force, it may result in a much higher motor current to rotate this nut.

Figure 7 shows the comparisons of three controllers. We can see that before $0.6 \mathrm{~s}$ these three speed curves are similar, while after $0.6 \mathrm{~s}$ the gradient of SMC speed curve changes due to the sliding surface effect. The NP speed curve gradient also changes based on the angle tracking error. For the bangbang controller, only if the target $492 \mathrm{rad}$ is reached, the control input will be changed. Hence, based on the analysis of Figure 7, it is easier to understand the motor angle curves in Figure 6.

Based on the analysis for Figures 6 and 7, we know the sliding mode control overmatches the other two control methods with respect to the tracking precision. From Figure 8, we will analyze the control input and the clamping force. In Figure 8(a), the duty cycle of control input is always 100 percent due to the large error before $0.6 \mathrm{~s}$. While from the period 0.6 to $0.77 \mathrm{~s}$ shown also in Figure $8(\mathrm{~b})$, it is obvious that the duty cycle is changing fast between 0 and 100 percent, since the trajectory is entering to the sliding surfaces. The clamping force is shown in Figure 8(c). And it can be seen, before $0.06 \mathrm{~s}$, that the clamping force is zero while during the same period the motor angle is increasing to $47 \mathrm{rad}$ as shown in Figures 8(c) and 6. That is because there is gap distance

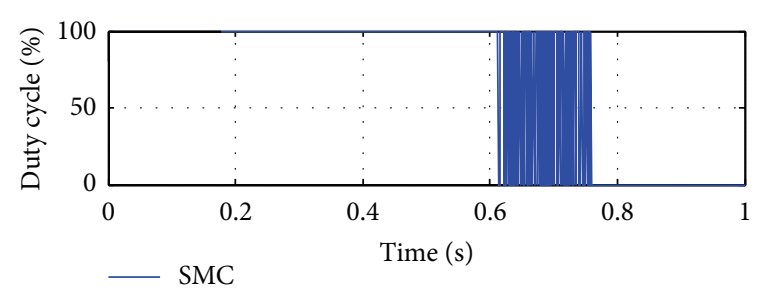

(a)

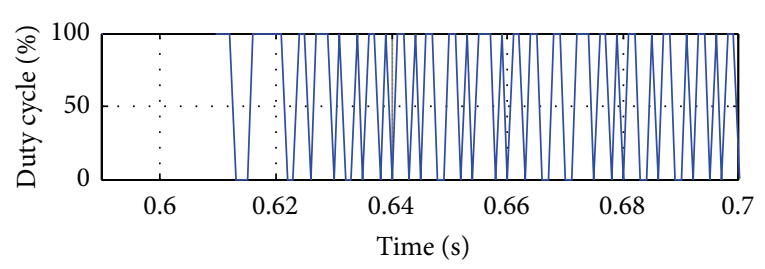

$-\mathrm{SMC}$

(b)

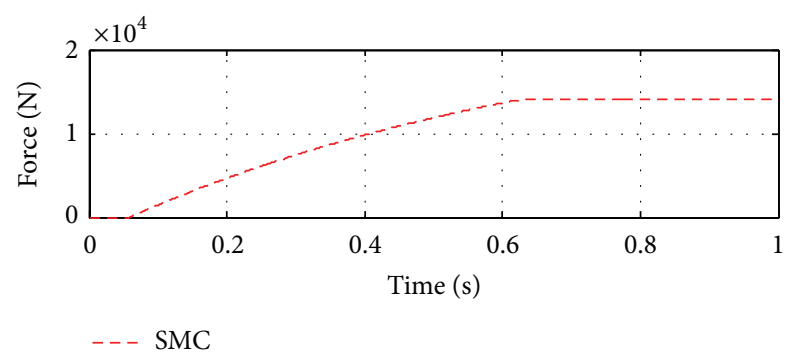

(c)

FIGURE 8: Duty cycle and clamping force under $\operatorname{SMC}\left(\theta_{d}=492 \mathrm{rad}\right)$.

between the nut and the disc that need be cleared first to generate the clamping force.

In order to testify the control robustness with respect to the setpoint value, the desired motor angle is chosen as $300 \mathrm{rad}$. As can be seen in Figure 9(a), all of these three curves can increase to the value around the target $300 \mathrm{rad}$ and hold steady. From Figure 9(b), it is obvious that the SMC curve reaches the target exactly, while the nonlinear $\mathrm{P}$ and Bangbang have $6.2 \mathrm{rad}$ and $13.6 \mathrm{rad}$ error, respectively.

From Figure 10, we can see that after $0.35 \mathrm{~s}$, the SMC speed curve converges to zero much more gently due to the sliding mode effect when compared with the other two curves. For nonlinear P controller, we can see that due to the nonlinear P control effect, the NP speed curve can change based on the angle error nonlinearly to improve the tracking performance compared with the bang-bang as seen in Figures 9 and 10.

From Figures 11(a) and 11(b), we can see the control input change. The duty cycle is constant 100 percent until $0.31 \mathrm{~s}$. When entering into the sliding surface, the duty cycle of the voltage changes fast to make the trajectory converge to zero. Note that in Figure 11(b), during the period $0.31 \mathrm{~s}-0.34 \mathrm{~s}$, the duty cycle is also zero. That is because in the first sliding surface $s_{1}=\dot{e}_{1}+g e_{1}$, the absolute value of angular speed is larger than the angle error, which results in the negative value of the sliding surface. Correspondingly, the duty cycle 


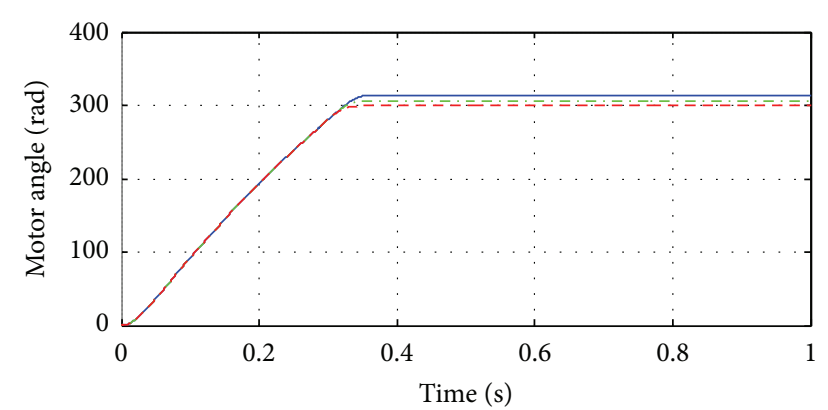

$-\mathrm{Bb}$
$--\mathrm{NP}$
$--\mathrm{SMC}$

(a)

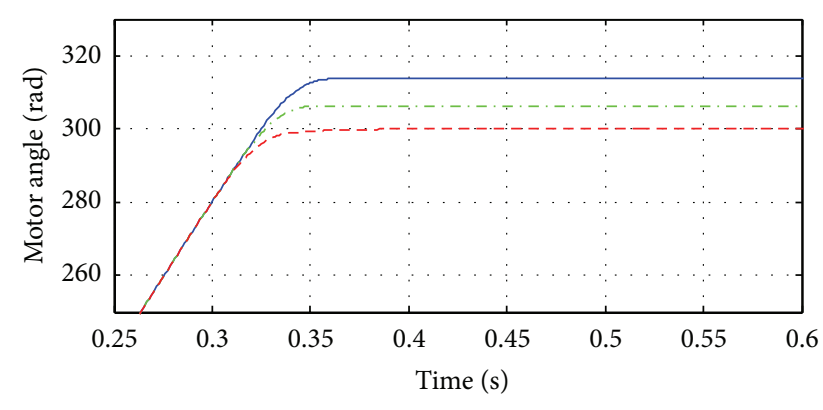

$-\mathrm{Bb}$
$-\ldots \mathrm{NP}$
$\ldots-\mathrm{SMC}$

(b)

Figure 9: Comparison among three control laws $\left(\theta_{d}=300 \mathrm{rad}\right)$.

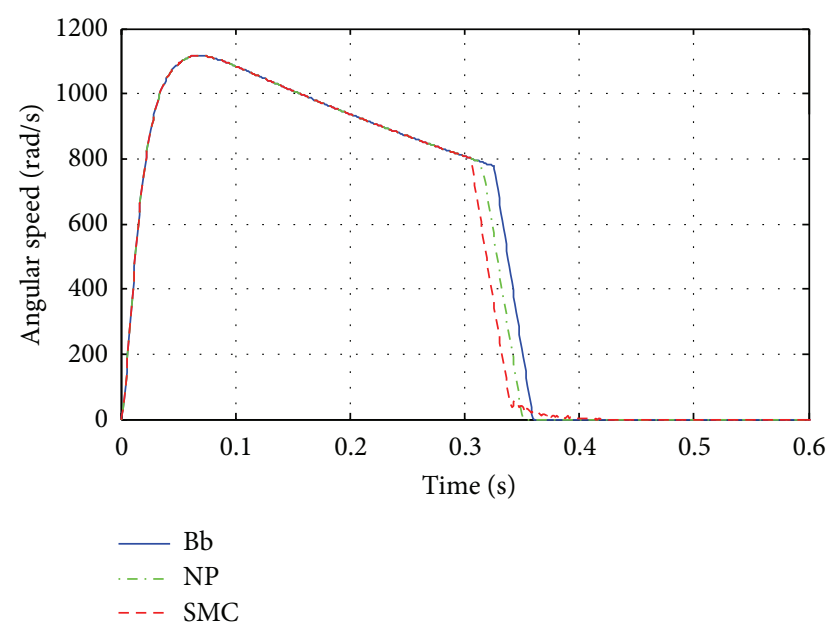

FIGURE 10: Motor speed comparisons among three control laws $\left(\theta_{d}=300 \mathrm{rad}\right)$.

will be the lowest value to attract the trajectory to zero from the negative orthant. Once the sliding surfaces $s_{1}=0, s_{2}=0$ are reached steadily, the motor power can be cut off. The corresponding clamping force is shown in Figure 11(c).

As can be seen in Figure 12, the values of the motor angle errors with three different controllers at each set-point

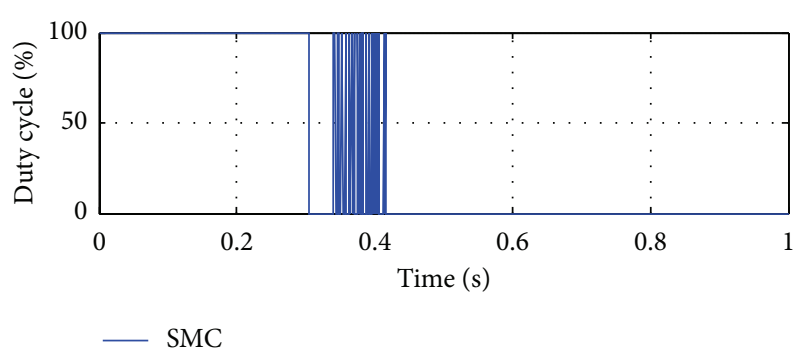

(a)

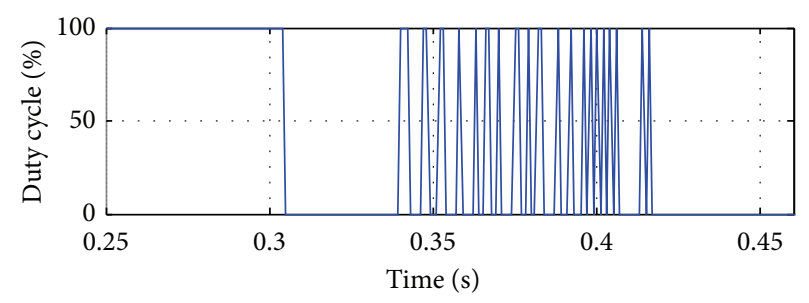

- SMC

(b)

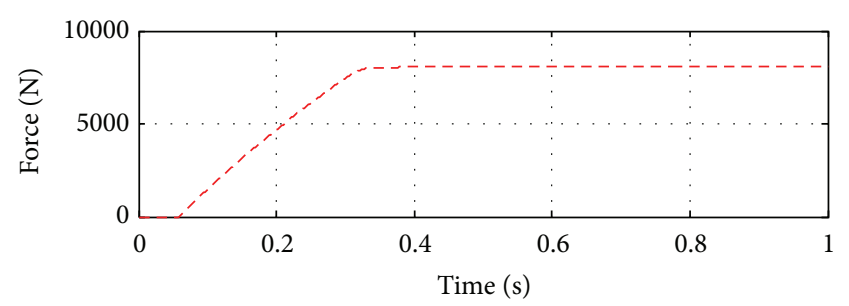

--- SMC

(c)

FIGURE 11: Duty cycle and clamping force under $\operatorname{SMC}\left(\theta_{d}=300 \mathrm{rad}\right)$.

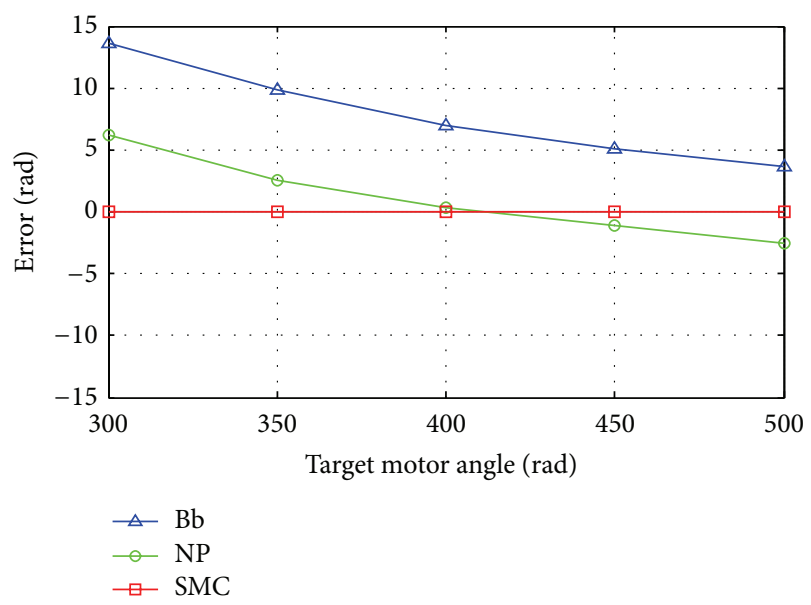

FIgURE 12: The motor angle errors with three controllers under various set-points.

are shown. The positive error implies the redundancy force while the negative erros means the insufficient displacement. Apparently, the SMC curve shows the best performance with no error during the whole targets. NP curve shows the best 


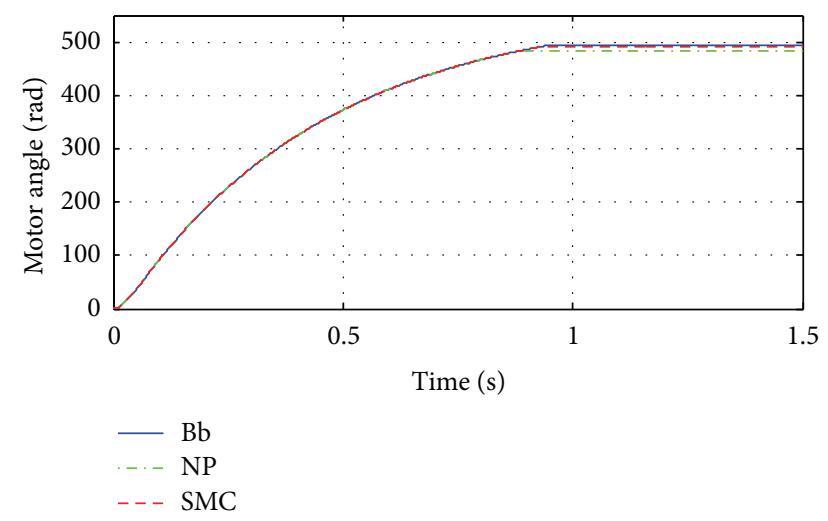

(a)

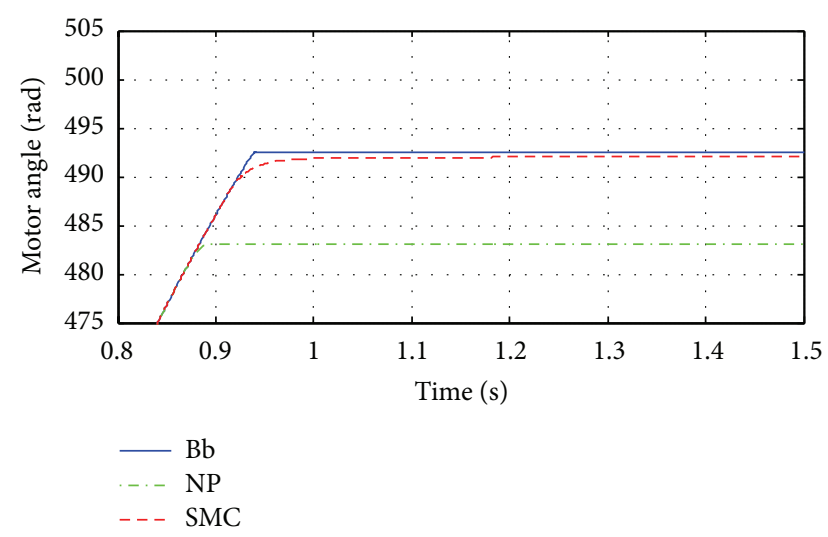

(b)

FIgURE 13: The motor angle errors with an increase in screw-nut friction coefficient $\left(\theta_{d}=492 \mathrm{rad}\right)$.

performance when the target is $400 \mathrm{rad}$, while on the other targets the absolute value of the error is increasing. The Bangbang controller shows the worst performance in terms of the precision, while the error is converging to zero with the increase of the target angle. This good trend may result from the lower angular speed at the power cut-off point.

It is possible that due to the wear of the actuator or the external effects, the friction coefficient of screw-nut system changes. We still take the desired value $492 \mathrm{rad}$ as an example to testify the robustness of these three controllers. The coefficient $\mu$ is assumed to change from 0.25 to 0.4 and the performance is shown in Figure 13. Apparently, the NP curve has a larger error, nearly $9 \mathrm{rad}$, compared with the desired value. Bang-bang shows a better performance with $0.5 \mathrm{rad}$ error, since with the increase of the friction coefficient the angular speed will be lower than the normal status at cutoff point. The SMC curve shows a very good robustness with respect to the friction ratio change.

\section{Conclusions}

In this paper, a sliding mode control method is utilized to control the clamping force on an integrated electric parking brake system. The working stages are analyzed with a graphical description. By means of the working stages analyses, the stage-switched state-space equations are given with the consideration of friction and system inertia. Based on the system structure from the stage-switched state-space, two sliding surfaces are developed to control the current and angular displacement, respectively. A common Lyapunov function is constructed to guarantee the control system stability. And through the reachability of SMC system, the control gain is also given in this paper. Through these two sliding surfaces, the angle degree set-point can be reached robustly with the gains the scope of which is obtained in the stability section. In the simulation section, three control methods are compared. For each set-point, the Bang-bang controller can track the target but always with a positive error which decreases with the rising of the target displacement; the nonlinear Proportional controller widely used in some published papers can track the target with less error than Bang-bang controller; however, it shows a poor robustness with respect to the friction and set-point variation; the proposed SMC method can track the desired value precisely and robustly. For various set-points, the SMC can track the target value by changing the control input quickly, and under the gain boundary it shows a good robustness with respect to the friction and set-point variation. Based on the relationship between the motor angle and clamping force, the future work is studying the dynamic braking control by IEPBs actuators.

\section{Appendix}

\section{Nonlinear P Control}

A nonlinear clamping force control law using nonlinear $\mathrm{P}$ control theory for traditional EPB system was developed by Lee et al. [3-7]. The control input can be written as

$$
u= \begin{cases}K_{p n l}|e|^{\alpha}, & \forall e>\delta>0 \\ K_{p\lrcorner l} \delta^{\alpha-1}, & \forall e \leq \delta \\ u_{\min }, & \forall e<0 .\end{cases}
$$

It applies high gain for small error and small gain for large error.

\section{Nomenclature}

$b_{v}: \quad$ Motor viscous friction coefficient

$b_{\text {brake }}$ : Damping coefficient of IEPBs

$d_{1}$ : $\quad$ Gap between the nut and piston

$d_{2}$ : Total thickness of pad and piston

$d_{3}: \quad$ Gap between the friction pad and disc

$E_{b}$ : Back-EMF voltage

$F_{f}: \quad$ Friction force

$F_{v}$ : Screw-nut viscous friction coefficient

$F_{\text {max }_{f}}:$ Maximum friction force

$F_{\mathrm{Q}}: \quad$ Axial load force

$i_{a}$ : $\quad$ Motor current

$J_{m}: \quad$ Moment of inertia

$k_{\text {brake }}$ : Stiffness coefficient of the brake system

$k_{\text {disk }}$ : Stiffness coefficient of brake disc

$k_{\text {head }}$ : Stiffness coefficient of nut

$k_{\mathrm{pad}}$ : Stiffness coefficient of pad 
$k_{\text {caliper: }}$ Stiffness coefficient of and the caliper

$K_{\text {emf }}$ : EMF constant

$K_{\text {motor }}$ : Motor torque constant

$L_{a}: \quad$ Inductance

$m_{\text {nut }}:$ Mass of nut

$N$ : $\quad$ Gear ratio

$R_{a}: \quad$ Resistance

$T_{m}$ : $\quad$ Motor torque

$T_{F}$ : $\quad$ Motor friction torque

$T_{L}$ : $\quad$ Screw torque

$T_{F C}$ : Motor dynamic friction torque

$T_{F \text { max }}$ : Motor maximum static friction torque

$u$ : Control input

$U: \quad$ Motor Voltage

$x_{\text {nut }}$ : Linear displacement of nut

$\alpha: \quad$ Screw lead angle

$\theta_{L}: \quad$ Angular position corresponding to gap

$\theta$ : Total angular displacement

$\omega$ : Motor angular velocity

$\omega_{s}: \quad$ Stribeck angular velocity

$\mu_{s}: \quad$ Sliding friction coefficient.

\section{Acknowledgments}

This work is partially supported by the Fundamental Research Funds for the Central Universities (Grant no. 2012-JL-11), China Scholarship Council Funding (Grant no. 201306950040), and the Wanxiang Group.

\section{References}

[1] S. Ralf, R. Isermann, J. Böhm et al., "Clamping force estimation for a brake-by-wire actuator," SAE 1999-01-0482, 1999.

[2] E. A. Bretz, "By-wire cars turn the corner," IEEE Spectrum, vol. 38, no. 4, pp. 1-7, 2001.

[3] Y. O. Lee, Y. S. Son, and C. C. Chung, "Clamping force control for an electric parking brake system: switched system approach," IEEE Transactions on Vehicular Technology, vol. 62, no. 7, pp. 2937-2948, 2013.

[4] Y. O. Lee, M. Jang, W. Lee, C. W. Lee, C. C. Chung, and Y. S. Son, "Novel clamping force control for electric parking brake systems," Mechatronics, vol. 21, no. 7, pp. 1156-1162, 2011.

[5] M. Jang, Y. O. Lee, W. Lee, C. W. Lee, C. C. Chung, and Y. Son, "Novel clamping force control for electric parking brake systems," in Proceedings of the 7th Asian Control Conference (ASCC '09), pp. 1588-1593, Hong Kong, China, August 2009.

[6] Y. O. Lee, C. W. Lee, H. B. Chung et al., "A nonlinear proportional controller for electric parking brake system," SAE 200701-3657, 2007.

[7] Y. O. Lee, C. W. Lee, C. C. Chung, Y. Son, P. Yoon, and I.-Y. Hwang, "Stability analysis of an Electric Parking Brake (EPB) systems with a nonlinear proportional controller," in Proceedings of the 17th World Congress, International Federation of Automatic Control, IFAC, pp. 14247-14253, Coex, South Korea, July 2008.

[8] C. W. Lee, H. B. Chung, Y. O. Lee, C. C. Chung, Y. S. Son, and P. Yoon, "Fault detection method for electric parking brake (EPB) systems with sensorless estimation using current ripples," International Journal of Automotive Technology, vol. 11, no. 3, pp. 387-394, 2010.
[9] K. Kondo and T. Watanabe, Parking brake control system US Patent 8296029 B2, 2012.

[10] S. Saric, A. Bab-Hadiashar, and R. Hoseinnezhad, "Clampforce estimation for a brake-by-wire system: a sensor-fusion approach," IEEE Transactions on Vehicular Technology, vol. 57, no. 2, pp. 778-786, 2008.

[11] C. Line, C. Manzie, and M. Good, "Control of an electromechanical brake for automotive brake-by-wire systems with an adapted motion control architecture," SAE 2004-01-2050, 2004.

[12] C. Jo, S. Hwang, and H. Kim, "Clamping-force control for electromechanical brake," IEEE Transactions on Vehicular Technology, vol. 59, no. 7, pp. 3205-3212, 2010.

[13] R. Leiter, "Design and control of an electric parking brake," SAE 2002-01-2583, 2002.

[14] W. Bin, G. Xuexun, Z. Chengcai et al., "Simulation and experiment on electrical parking brake system," Transactions of the Chinese Society for Agricultural Machinery, vol. 44, no. 8, pp. 4549, 2013.

[15] TRW, http://www.trw.com/braking_systems/electric_park_brake/ epb.

[16] Mercedes Benz 216 Electric parking brake Control Units, http:// www.micro-tronik.com/mercedes_benz_216_electric_parking brake_(efb)_235.html.

[17] S. Saric, A. Bab-Hadiashar, and J. V. D. Walt, "Estimating clamp force for brake-by-wire systems: thermal considerations," Mechatronics, vol. 19, no. 6, pp. 886-895, 2009.

[18] H. Zhang, Y. Shi, and J. Wang, "Observer-based tracking controller design for networked predictive control systems with uncertain Markov delays," International Journal of Control, vol. 86, no. 10, pp. 1824-1836, 2013.

[19] H. Zhang, Y. Shi, and M. Liu, "Ho step tracking control for networked discrete-time nonlinear systems with integral and predictive actions," IEEE Transactions on Industrial Informatics, vol. 9, no. 1, pp. 337-345, 2013.

[20] P. Kachroo and M. Tomizuka, "Chattering reduction and error convergence in the sliding-mode control of a class of nonlinear systems," IEEE Transactions on Automatic Control, vol. 41, no. 7, pp. 1063-1068, 1996.

[21] H. Zhang, J. Wang, and Y. Shi, "Robust Ho sliding-mode control for Markovian jump systems subject to intermittent observations and partially known transition probabilities," Systems \& Control Letters, vol. 62, no. 12, pp. 1114-1124, 2013.

[22] H. Zhang, Y. Shi, and A. Saadat Mehr, "Robust static output feedback control and remote PID design for networked motor systems," IEEE Transactions on Industrial Electronics, vol. 58, no. 12, pp. 5396-5405, 2011.

[23] J. Zhang, Y. Tong, X. Zi et al., "Electronic parking brake actuator with cable," Chinese Patent 201120276953.2.

[24] Y. Yong, W. Haotian, G. Xuexun et al., "Design of test bench of the electronic parking brake system," Chinese Automobile Technology, vol. 11, no. 1, pp. 40-45, 2012.

[25] H. Olsson, K. J. Åström, C. C. D. Wit, M. Gäfvert, and P. Lischinsky, "Friction models and friction compensation," European Journal of Control, vol. 4, no. 3, pp. 1-37, 1998.

[26] O. Vahid and F. Golnaraghi, Friction-Induced Vibration in Lead Screw Drives, Springer, New York, NY, USA, 2011.

[27] R. C. Juvinall and K. M. Marshek, Fundamentals of Machine Component Design, John Wiley \& Sons, New York, NY, USA, 1999. 
[28] O. Vahid, N. Eslaminasab, and M. F. Golnaraghi, "Frictioninduced vibration in lead screw systems: mathematical modeling and experimental studies," Transactions of the ASME, vol. 131, no. 2, pp. 1-10, 2009.

[29] H. Zhang, Y. Shi, and A. S. Mehr, "Robust weighted Ho filtering for networked systems with intermittent measurements of multiple sensors," International Journal of Adaptive Control and Signal Processing, vol. 25, no. 4, pp. 313-330, 2011. 


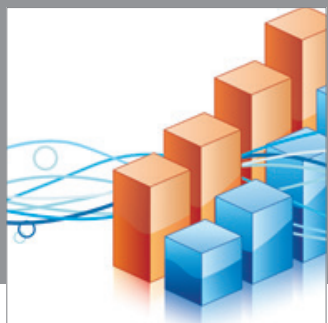

Advances in

Operations Research

mansans

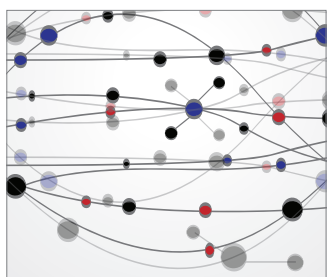

The Scientific World Journal
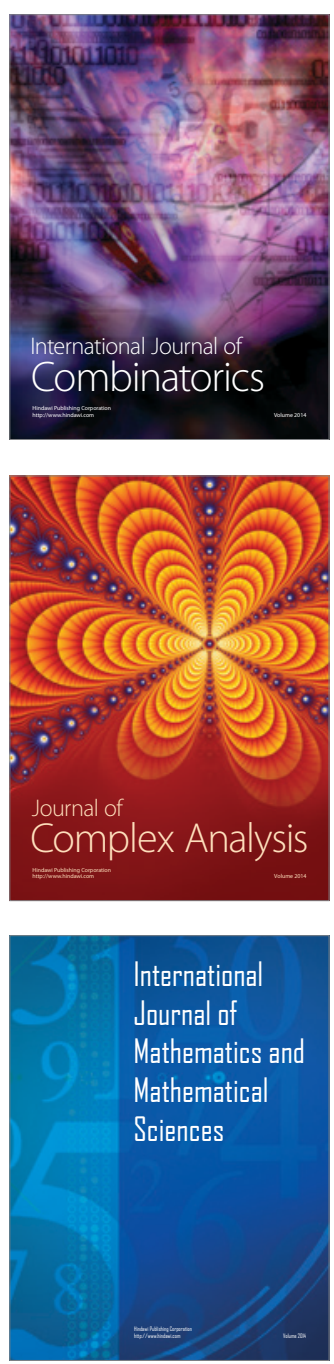
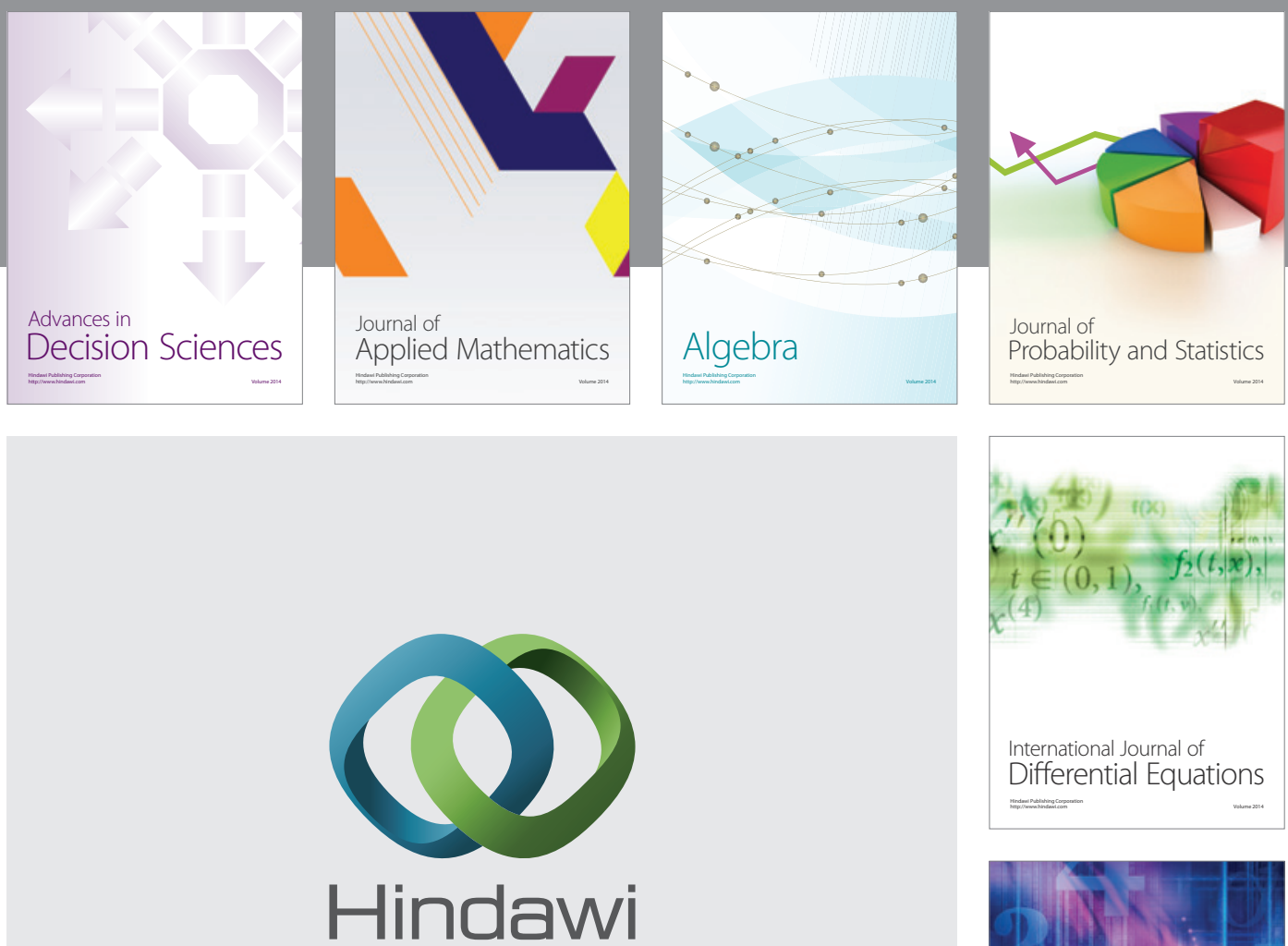

Submit your manuscripts at http://www.hindawi.com
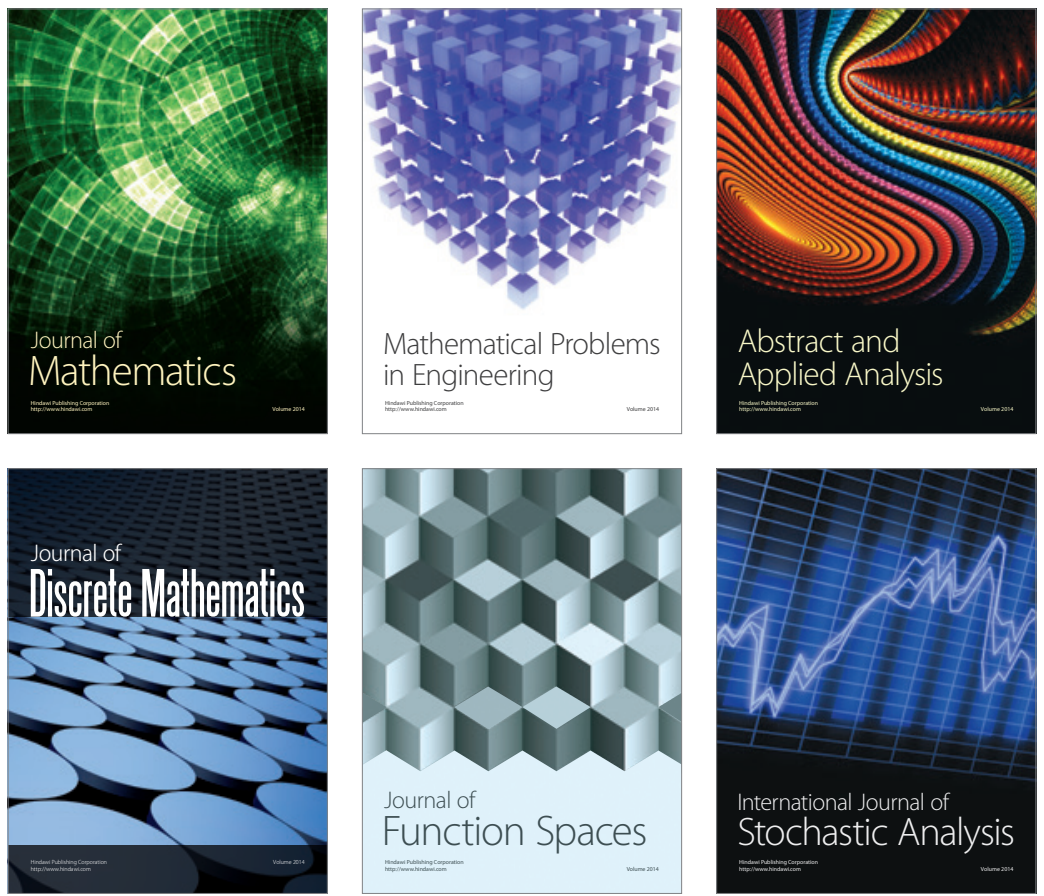

Journal of

Function Spaces

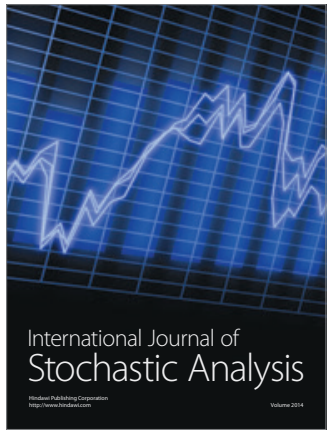

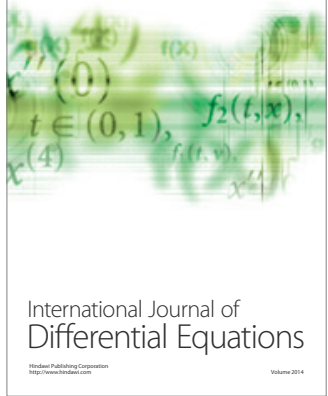
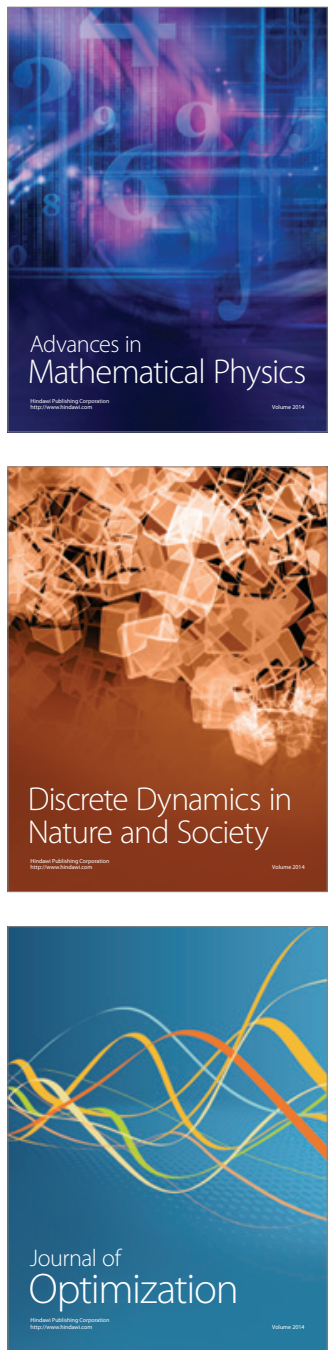